\title{
Clinicopathologic features of endometrial cancer with mismatch repair deficiency
}

\author{
Sushmita Gordhandas ${ }^{1}$, Ryan M Kahn ${ }^{1}$, Charlotte Gamble², Nizam Talukdar², Brandon Maddy ${ }^{1}$, Becky Baltich Nelson ${ }^{3}$, Gulce Askin4, Paul J \\ Christos $^{4}$, Kevin Holcomb² ${ }^{2}$ Thomas A Caputo², Eloise Chapman-Davis ${ }^{2}$ and Melissa K Frey²
}

${ }^{1}$ Department of Obstetrics and Gynecology, Weill Cornell Medical College, New York, NY, USA

${ }^{2}$ Division of Gynecologic Oncology, Department of Obstetrics and Gynecology, Weill Cornell Medical College, New York, NY, USA

${ }^{3}$ Department of Information Technologies and Services, Weill Cornell Medical College, New York, NY, USA

${ }^{4}$ Division of Biostatistics and Epidemiology, Department of Healthcare Policy \& Research, Weill Cornell Medicine, New York, NY, USA

\section{Abstract}

The inclusion of DNA mismatch repair (MMR) evaluation as a standard of care for endometrial cancer management will result in a growing population of patients with MMR deficiency and negative germline Lynch syndrome testing (MMR-deficient). In this systematic review and study, the clinicopathologic features of endometrial cancer in patients with MMR-intact, MLH1 methylation positive, MMR-deficient or Lynch syndrome are evaluated. A systematic search of online databases between 1990 and 2018 identified studies of endometrial cancer patients with tumour testing (MMR protein immunohistochemistry or microsatellite instability) and germline assessment for Lynch syndrome. Extracted data included tumour testing, germline genetic testing, age, body mass index (BMI), family history, tumour stage, grade and histologic type. Associations between MMR-intact, MLH1 methylation positive, MMR-deficient and Lynch syndrome groups were analysed using descriptive statistics. The comprehensive search produced 4,400 publications, 29 met inclusion criteria. A total of 7,057 endometrial cancer cases were identified, 1,612 with abnormal immunohistochemistry, 977 with microsatellite instability. Nine-hundred patients underwent germline genetic testing, identifying 212 patients with Lynch syndrome. Patients in the Lynch syndrome and MMR-deficient groups were significantly younger than patients in the MMR-intact and MLH1 methylation positive groups. Patients with MMR-intact tumours had the highest BMI, followed by MMRdeficient, then Lynch syndrome. MMR-intact tumours were more likely to be grade I at diagnosis than other groups. Patients with Lynch syndrome and MMR-deficient tumours were less likely to have stage I disease as compared to patients with MMR-intact tumours. Endometrial cancer patients with MMR-deficient tumours have similar features to those with germline Lynch syndrome mutations, including age, grade, histology and stage. Even in the absence of a germline mutation, tumour evaluation for MMR status may have important clinical implications.

Keywords: microsatellite instability, mismatch repair endonuclease PMS2, MutS homolog 2 protein, EPCAM protein, human, epithelial cell adhesion molecule, immunohistochemistry, DNA mismatch repair, MLH1 protein, human, MutL protein homolog 1, neoplastic syndromes, hereditary, endometrial neoplasms, DNA, risk assessment

Correspondence to: Sushmita Gordhandas Email: sbg9005@nyp.org

ecancer 2020, 14:1061

https://doi.org/10.3332/ecancer.2020.1061

Published: $18 / 06 / 2020$

Received: 18/02/2020

Publication costs for this article were supported by ecancer (UK Charity number 1176307).

Copyright: (c) the authors; licensee ecancermedicalscience. This is an Open Access article distributed under the terms of the Creative Commons Attribution License (http:// creativecommons.org/licenses/by/3.0), which permits unrestricted use, distribution, and reproduction in any medium, provided the original work is properly cited. 


\section{Introduction}

In contrast to most solid tumours, the incidence and deaths from endometrial cancer continue to rise [1]. It is estimated that currently there are over 727,000 people in the United States living with endometrial cancer, with approximately 63,230 new cases and 11,315 deaths reported in 2018 [2, 3]. One proposed strategy to improve endometrial cancer outcomes is to abandon the traditional two-tiered endocrine based classification and move towards molecular tumour analysis [4]. Examples of such intiatives include The Cancer Genome Atlas (TCGA) and Proactive Molecular Risk Classifier for Endometrial Cancer (ProMisE) which all aim to identify prognostic signatures through specific molecular criteria [5, 6]. In 2014, the American College of Obstetricians and Gynecologists and Society of Gynecologic Oncology recommended that all endometrial tumours undergo molecular screening for mismatch repair (MMR) deficiency [7].

Evaluation of endometrial tumours for MMR deficiency can identify patients with Lynch syndrome, an autosomal dominant mutation in the DNA of MMR proteins (MLH1, MSH2, MSH6 or PMS2 and EPCAM). Approximately 1 in 279 to 1 in 400 individuals is affected by Lynch syndrome and $3 \%$ of endometrial cancers are attributable to Lynch syndrome [8, 9]. The lifetime risk of endometrial cancer among patients with Lynch syndrome varies by gene: MLH1 and MSH2 25\%-60\%, MSH6 16\%-26\%, and PMS2 15\% [10]. MMR deficiency is typically evaluated via immunohistochemistry (IHC) for MMR protein expression, polymerase chain reaction assessment of DNA microsatellite instability (MSI) and MLH1 promotor methylation analysis [11]. Based on a large meta-analysis, $28 \%$ of endometrial tumours will exhibit abnormal MMR IHC, and $31 \%$ have MSI. However, the majority of patients with abnormal MMR testing will not have an underlying Lynch syndrome mutation (15\% of patients with abnormal IHC, and 19\% with MSI) [9].

As more patients undergo MMR testing, there will be a growing population of patients found to have abnormal MMR testing and negative germline testing for Lynch syndrome [9].This group will be referred to as MMR-deficient for the remainder of this paper. Recommendations from the National Comprehensive Cancer Network (NCCN) for the MMR-deficient group are vague, mentioning 'tailored surveillance based on individual and family risk assessment'[10]. As endometrial cancer becomes a more heterogenous disease based on molecular profiling, an understanding of the pathologic and clinical implications of this stratification systems is imperative. Studies are beginning to find differences in outcomes between MMR-deficient, MLH1 methylation positive, and MMR-intact endometrial cancers [12]. Furthermore, MMR status has a growing role in guiding management [13]. The aim of this study and systematic review is to evaluate the clinicopathologic features of patients with MMR-intact, MLH1 methylation positive, MMR-deficient and Lynch syndrome endometrial cancers in order to better understand this expanding population.

\section{Methods}

\section{Strategy for search and selection criteria}

This systematic review was registered with PROSPERO (\#84957), the international prospective register of systematic reviews, and followed the guidelines of the Preferred Reporting Items for Systematic Reviews and Meta-Analyses (PRISMA) statement [14]. This study provides additional analysis of data from a previously published meta-analysis reviewing tumour testing and diagnosis of Lynch syndrome [9].

A comprehensive literature search was conducted by the institutional medical librarian team on January 11,2018 using the following bibliographic databases from inception: Ovid MEDLINE $®$ (In-Process \& Other Non-Indexed Citations and Ovid MEDLINE ${ }^{\circledR} 1946$ to Present), Ovid EMBASE (1974 to present), and The Cochrane Library (Wiley). No language, publication date, or article type restrictions were included in the search (full Ovid MEDLINE search strategy is available in Supplementary Table 1). To be eligible, articles had to meet the following inclusion criteria: studies of patients with known endometrial cancer, studies whose patients underwent tumour testing with MMR IHC and/ or MSI analysis, and studies whose patients underwent germline genetic testing for Lynch syndrome following positive screening. Exclusion criteria included: studies only regarding nonendometrial cancers, and studies whose subjects did not undergo genetic testing for Lynch syndrome. Both prospective and retrospective studies were included. The primary outcome was to describe the age, grade, stage, histology, and body mass index (BMI) of these groups using a systematic review approach. 


\section{Data extraction}

The number of patients with normal or abnormal IHC (for MLH1, MSH2, MSH6 or PMS2 genes), MLH1 methylation, and MSI was extracted from each study if available (Supplementary Table 2). Data on age, BMI, family history criteria, tumour stage, tumour grade and histologic type were obtained when available (Supplementary Table 2). These variables were chosen because they were most commonly studied and reported.

Data were separated by MMR-intact, MLH1 methylation positive, MMR-deficient or Lynch syndrome. MMR-intact included patients with normal MMR tumour testing (IHC and/or MSI). As noted previously, the MMR-deficient group included patients with abnormal MMR tumour testing and negative germline testing for Lynch syndrome mutations. Lynch syndrome included patients with abnormal MMR tumour testing and positive germline testing for Lynch syndrome mutations. Three independent investigators retrieved, entered, and exported data from the Covidence online software program.

\section{Statistical analysis}

Associations between Lynch syndrome, MMR-deficient, MLH1 methylation positive and MMR-intact groups were analysed using descriptive statistics. As presented in Supplementary Table 2, not all studies reported the clinicopathologic variables of interest. Studies that reported on any of the six variables were included in analysis.

The mean age and BMI were weighted based on the number of patients per study. Four studies had inclusion criteria of patients less than 50-year old, and therefore were excluded from calculation of mean age [15-18]. Only studies that reported a number of patients with a mean age/ BMI value were included in calculation of mean age and BMI for each group.

Associations between each cohort for continuous variables were conducted using $t$-test and analysis of variance. Post hoc (Tukey) tests were conducted between the four groups in analysis of variance testing and further analyzed using $t$-test for those that were statistically significant. For categorical variables, the four groups were analysed using chi-square. Test of significance was measured using two-tailed tests with a 95\% acceptable error, $p$-value 0.05. All analyses were conducted with the use of Statistical Analysis System (SAS) software version 9.4 (SAS Institute).

\section{Results}

\section{Search results}

A total of 6,773 studies were identified from the database search. All were imported into Covidence and duplicates were removed. The remaining 4,400 studies were screened by title and abstract against predetermined inclusion and exclusion criteria by three independent reviewers, with discrepancies resolved by consensus. Ninety-two articles were selected for full text review. Both reference and relevant article lists for these studies were gathered and duplicates were removed, producing 973 additional citations for review; none of these were selected for full text review. From the full text review, 29 articles met inclusion criteria (Figure 1, Supplementary Table 2) [15-43]. These studies were also described in a previously published meta-analysis reviewing tumour testing and diagnosis of Lynch syndrome [9].

\section{Patient characteristics}

From the 29 included articles, 7,057 endometrial cancer cases were identified. Mean age of included patients was 59.7 years (range 35.764.6 years). Tumour histology included endometrioid (3,316, 86\%), mixed (232, 6\%), serous (166, 4\%), carcinosarcoma (79, 2\%), clear cell (36, 1\%) and adenosquamous (16, 0.4\%). Fifty-six percent of patients (2295) had grade 1 tumours, 26\% (1062) grade 2 and 18\% (736) grade 3. At time of diagnosis, 79\% (2745) of patients were stage I, 6\% (221) stage II, 13\% (439) stage III and 2\% (71) stage IV (Table 1). 


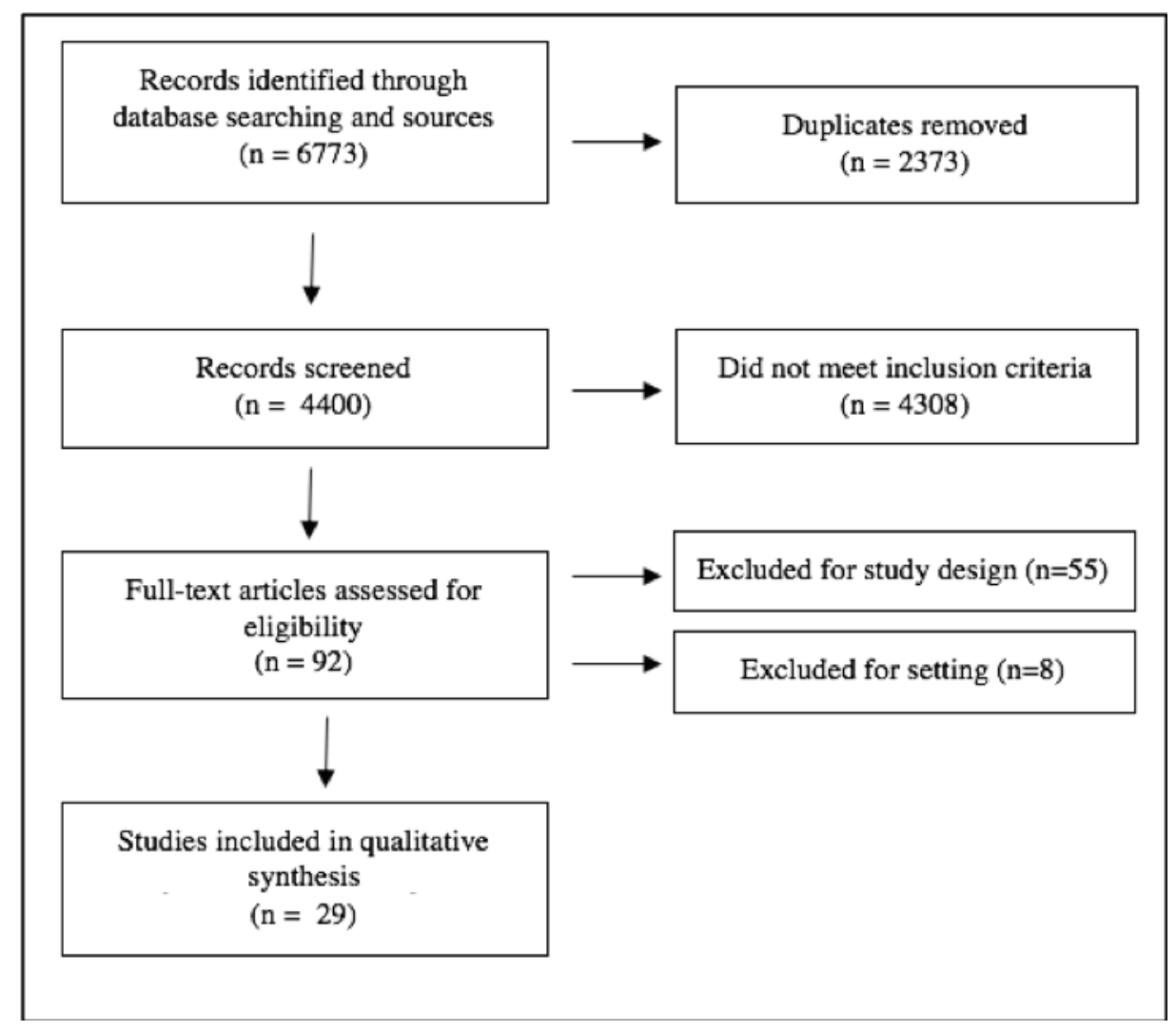

Figure 1. PRISMA flowchart of article search algorithm for systematic review.

Table 1. Overall patient demographics and clinicopathologic findings.

\begin{tabular}{|l|c|}
\hline \multicolumn{1}{|c|}{ Mean age- years (range) } & $59.7(35.7-64.6)$ \\
\hline 1 & $2,295(56 \%)$ \\
\hline 2 & $1,062(26 \%)$ \\
\hline 3 & $736(18 \%)$ \\
\hline Tumour grade (n, \%) & \multicolumn{1}{|c|}{} \\
\hline Endometrioid & $3,316(86 \%)$ \\
\hline Mixed & $232(6 \%)$ \\
\hline Serous & $166(4 \%)$ \\
\hline Carcinosarcoma & $79(2 \%)$ \\
\hline Clear cell & $36(1 \%)$ \\
\hline Adenosquamous & $16(0.4 \%)$ \\
\hline Tumour Stage (n, \%) & \\
\hline I & $2,745(79 \%)$ \\
\hline II & $221(6 \%)$ \\
\hline III & $439(13 \%)$ \\
\hline IV & $71(2 \%)$ \\
\hline
\end{tabular}


Among the included patients, 6,325 (90\%) underwent MMR tumour assessment via IHC and 3,140 (44\%) via MSI analysis. Of the patients undergoing IHC, 1,612 had abnormal IHC staining for MMR proteins (1,162 MLH1 absent, 450 MSH2, MSH6 or PMS2 absent). If MLH1 was absent, MLH1 promoter methylation was evaluated in the majority of studies (Supplementary Table 2). If known, MLH1 promoter methylation positive tumours were not included in the MMR-deficient group. Of patients undergoing MSI analysis, 977 had MSI and 2,163 were microsatellite stable (Table 2).

Nine hundred patients underwent germline genetic testing, identifying 212 (24\%) patients with Lynch syndrome. Six hundred eighty-eight (76\%) patients were MMR-deficient (with negative germline mutation testing). Lynch syndrome was diagnosed in 3\% of the total population and $13 \%$ of the population with abnormal tumour testing.

\section{Clinicopathologic findings}

Five clinicopathologic variables were studied: age, grade, stage, histology and BMI at time of endometrial cancer diagnosis, presented in Table 3. For age at diagnosis, MMR-deficient and Lynch syndrome were similar (52.5 versus 51.4 years, respectively, $p=0.08$ ). Patients with MLH1 methylation positive tumours were significantly older than MMR-intact patients (64.2 versus 61.6 years, respectively, $p<0.01$ ). Patients with Lynch syndrome and MMR-deficient tumours were significantly younger than patients with MMR-intact, and MLH1 methylation positive tumours $(p<0.01)$.

Tumour grade was similar in MMR-deficient, MLH1 methylation positive and Lynch syndrome. Patients with MMR-intact tumours were most likely to be diagnosed with low-grade disease, with 58\% having FIGO grade I endometrial cancer. MMR-deficient, MLH1 methylation positive and Lynch syndrome tumours were significantly less likely to be grade I than MMR-intact tumours (39\% mismatch repair-deficient, 31\% MLH1 methylation positive, $41 \%$ Lynch syndrome $(p<0.01))$.

Tumours with MMR-intact were significantly more likely to be endometroid histology than Lynch syndrome-associated tumours (87\% versus $80 \%$, respectively, $p<0.01$ ). Ninety-one percent of MLH1 methylation positive tumours were endometrioid histology, significantly more than MMR-intact and Lynch syndrome $(p<0.01)$. Stage at diagnosis was similar between MMR-deficient, and Lynch syndromes patients, both of these groups were significantly less likely to be diagnosed as stage I when compared to MMR-intact tumours (70\% and $67 \%$ versus $81 \%$, respectively, $p<0.01$ ).

BMI was significantly different when comparing MMR-intact, MMR-deficient and Lynch syndrome cases. Patients with MMR-intact had the highest BMI $\left(35.7 \mathrm{~kg} / \mathrm{m}^{2}\right)$, followed by MMR-deficient $\left(34.6 \mathrm{~m} \mathrm{~kg} / \mathrm{m}^{2}\right)$ and Lynch syndrome $\left(27.6 \mathrm{~kg} / \mathrm{m}^{2}\right)(p<0.01$ for all comparisons).

Among the total population with available family history data, 30\% met family history-based criteria for genetic assessment (Amsterdam and/ or Bethesda criteria). MMR-deficient and MMR-intact patients were less likely to meet family history based criteria for germline testing than patients who were ultimately diagnosed with Lynch syndrome ( $13 \%$ and $19 \%$ versus $54 \%, p<0.01$ ) (Table 4$)$. None of the studies evaluated $\mathrm{BMI}$ or family history among patients with MLH1 methylation testing.

Table 2. Molecular tumour testing results.

\begin{tabular}{|c|c|}
\hline \multicolumn{1}{|c|}{ Population } & N \\
\hline Total population & 7,057 \\
\hline Abnormal IHC & 1,612 \\
\hline MLH1 absent & 1,162 \\
\hline MLH1 methylation negative & 166 \\
\hline MLH1 methylation positive & 996 \\
\hline MSH2, MSH6, or PMS2 absent & 450 \\
\hline Microsatellite insufficiency & 977 \\
\hline
\end{tabular}




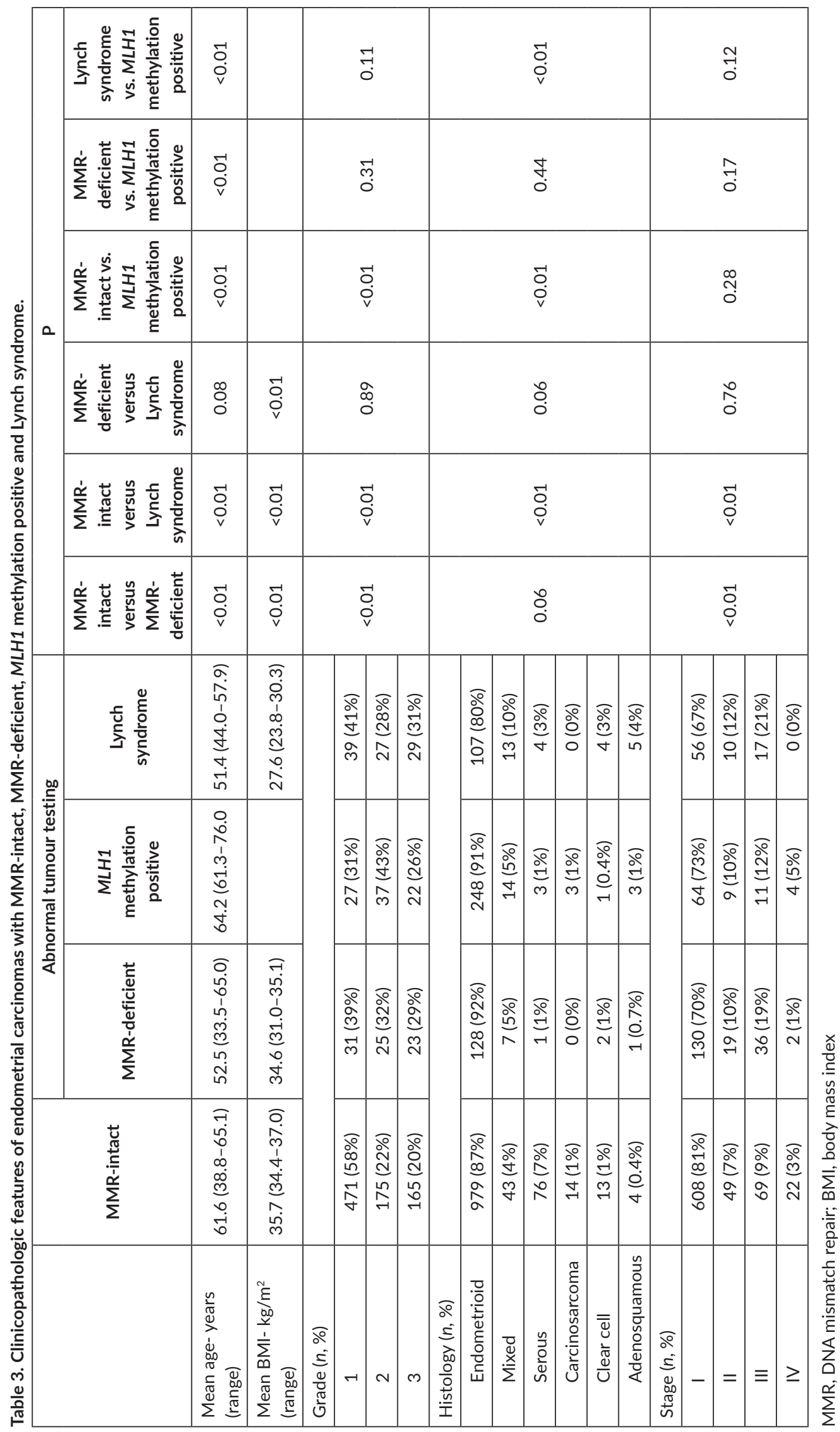


Table 4. Family history based criteria* for germline testing with MMR-intact, MMR-deficient and Lynch syndrome.

\begin{tabular}{|l|l|c|c|c|c|c|c|c|}
\hline \multicolumn{2}{|c|}{} & \multirow{2}{*}{$\begin{array}{c}\text { Overall } \\
(N=456)\end{array}$} & $\begin{array}{c}\text { MMR-intact } \\
(N=146)\end{array}$ & $\begin{array}{c}\text { MMR-deficient } \\
(N=148)\end{array}$ & $\begin{array}{c}\text { Lynch syndrome } \\
(N=162)\end{array}$ & $\begin{array}{c}\text { MMR-intact versus } \\
\text { MMR-deficient }\end{array}$ & $\begin{array}{c}\text { MMR-intact versus } \\
\text { Lynch syndrome }\end{array}$ & $\begin{array}{c}\text { MMR-deficient versus } \\
\text { Lynch syndrome }\end{array}$ \\
\hline \multirow{2}{*}{$\begin{array}{l}\text { Family } \\
\text { history* }\end{array}$} & Yes & $135(30 \%)$ & $28(19 \%)$ & $19(13 \%)$ & $88(54 \%)$ & \multirow{2}{*}{0.13} & $<0.01$ \\
\cline { 2 - 5 } & No & $321(70 \%)$ & $118(81 \%)$ & $129(87 \%)$ & $74(46 \%)$ & $<01$ \\
\hline
\end{tabular}

*Family history based criteria defined as Amsterdam and/or Bethesda criteria, per study.

\section{Discussion}

In this systematic review of 29 published studies and 7,057 patients, tumour testing in endometrial cancer helped classify groups of patients with similar clinicopathologic characteristics. The majority of patients with abnormal tumour MMR screening were negative for Lynch syndrome on germline testing (688/900, 76\%), and therefore classified as MMR-deficient. We evaluated the clinicopathologic implications of this molecular finding with the hope of improving personalized disease management and patient counseling.

We found that MMR-deficient and Lynch syndrome groups were diagnosed with endometrial cancer at earlier ages compared to patients with MMR-intact (52.5 and 51.4 years versus 61.6 years respectively, $p<0.01$ ). Younger age at diagnosis has been described in prior studies on MMR-deficient endometrial cancer [27]. Additionally, this reflects results seen in colorectal cancer literature where patients with Lynch syndrome and MMR-deficient tumours are also diagnosed at earlier ages than MMR-intact patients [27, 44].

Patients with Lynch syndrome were less likely to have endometrioid endometrial cancer than patients with MMR-intact tumours (80\% versus $87 \%, p<0.01$ ). This reinforces previous literature showing that Lynch syndrome is associated with more heterogenous histologies [45]. Given the small sample size of patients with other histologies (serous, carcinosarcoma, clear cell and adenosquamous), no significant differences were identified amongst the cohorts.

Our data shows that BMI was highest among patients with MMR-intact tumours $\left(35.7 \mathrm{~kg} / \mathrm{m}^{2}\right)$, followed by MMR-deficient and Lynch syndrome (32.6 and $27.6 \mathrm{~kg} / \mathrm{m}^{2}$, respectively, $p<0.01$ ). Therefore, obesity-an established risk factors for endometrial cancer-may not be associated with MMR defects. Previous endometrial cancer studies have reported mixed results when comparing BMI measurements between these groups $[30,46]$. Our results, with a large sample size, suggest that genetic and epigenetic changes in MMR expression, rather than obesity, may drive the development of endometrial cancer in these populations.

The role of family history in genetic risk assessment is changing with growing utilisation of tumour molecular testing. There are various barriers that can inhibit obtaining an accurate family history. Because of this, family history-based testing is sensitive, but not specific, as $46 \%$ of patients in this study with Lynch syndrome did not have a family history that would warrant guideline-based genetic assessment. Only $13 \%$ of patients with MMR-deficient tumours met family history criteria. Patients with MMR-deficient tumours and MMR-intact tumours were less likely to meet family history criteria compared to those with Lynch syndrome ( $p<0.01)$. This supports the understanding of MMR-deficiency as a sporadic change in the tumour that is not driven by germline mutations. This is also described in the colorectal cancer literature. In a 2013 observational cohort study of 1,705 colorectal cancer patients, Rodríguez-Soler et al [47] demonstrated the incidence of colorectal cancer in families of patients with MMR-deficient tumours was significantly lower than in families of patients with Lynch syndrome but higher than in families of patients with MMR-intact $(p<0.001)$.

In colorectal cancer, Lynch syndrome has been associated with lower stage and decreased risk of distant metastases at time of diagnosis when compared to the general population [48, 49]. However, in endometrial cancer we exhibited the opposite. Lynch syndrome and MMRdeficient endometrial cancers were less likely to present at stage I compared to patients with MMR-intact $(p<0.01)$.

The role of MLH1 methylation as a prognostic factor is under evaluation. Current literature suggests that patients with MLH1 promoter methylation have tumours that are larger, more deeply invasive, and likely to exhibit lympho-vascular space invasion compared to those without 
[12]. Cosgrove et al [12] suggests this could be explained by chemoresistance exhibited by MMR defective tumours with MLH1 methylation. Our study shows that MLH1 methylation positive, and MMR-deficient tumours were diagnosed at higher grade when compared to MMRintact tumours. Additionally, patients with $\mathrm{MLH} 1$ methylation positive tumours were diagnosed at a significantly older age than other groups.

To the author's best knowledge, given the wide net of MMR-deficient patients included, this is one of the largest studies of patients with MMR-deficient endometrial cancer at this time. However, the MMR-deficient group may contain patients with unknown MLH1 methylation status. MLH1 methylation analysis and reporting varied between studies. MSI due to MLH1 hypermethylation was not identified in studies that performed MSI analysis alone. Eleven studies did not report data on MLH1 analysis, of which seven did not perform any MLH1 methylation analysis (Supplementary Table 2) [15,16, 18, 19, 21, 33, 34, 37, 39, 40, 41].

Another limitation was the inconsistent reporting of clinicopathologic data and inclusion criteria amongst the different studies, resulting in a heterogeneous patient population. Because this was a retrospective systematic review, we were unable to control for subgroups amongst the cohorts which could have led to a bias of statistical findings. Additionally, most of the studies did not include follow up, therefore, data comparing clinical outcomes of MMR deficiency with and without Lynch syndrome are limited. Previous studies are mixed with some suggesting worse outcomes for patients with MMR defects, while others suggest improved or no difference in outcome [50-57]. In a meta-analysis from 2013, Diaz-Padilla et al [58] found no definitive evidence of a significant association between MMR status and survival in endometrial cancer.

On analysis of the TCGA subgroups (p53-mutant, MSI, POLE-mutant, and no specific molecular profile (NSMP)), prognosis was unfavourable in the p53- mutant group, intermediate in the MSI and NSMP group, and the POLE-mutant group had a favourable prognosis [6, 59].

In a recent publication by Backes et al, patients with high-intermediate risk endometrioid endometrial cancer and abnormal MMR expression had increased risk of recurrence and decreased recurrence-free survival compared with MMR-intact tumours [60]. In colorectal cancer, prior studies also demonstrate overall survival benefit with abnormal tumour testing [49].

Although the goal of tumour MMR screening was initially to identify patients at risk of carrying a Lynch syndrome mutation, we now see that tumour screening-even among Lynch syndrome negative patients-may have clinical implications. In May 2017, the US. Food and Drug Administration granted accelerated approval of Pembrolizumab for treatment of microsatellite-instability-high or deficient MMR, irrespective of tumour site or organ involved [13]. As a result, patients with MMR-deficient endometrial tumours now have access to indicated targeted therapy irrespective of Lynch syndrome status.

\section{Conclusions}

This systematic review and study of the clinicopathologic features of endometrial cancers found that patients with MMR-deficient tumours have similar clinical features to those with germline Lynch syndrome which include age at diagnosis, grade, histology and stage. These findings will assist in patient counseling regarding results and interpretations of MMR testing. Further studies, including prospective designs, are necessary to better clarify the predictive and therapeutic implications of MMR-deficient endometrial cancers, and to help establish definitive management guidelines.

\section{Authors' contributions}

All authors have made substantial contributions to the conception/ design of the work, the acquisition, analysis, interpretation of data, the drafting of the work, and/or its critical revision for important intellectual content. All authors have given final approval of the version to be published.

\section{Conflicts of interest statement}

The authors declare that they have no conflicts of interest. 


\section{Funding declaration}

Paul Christos, DrPH and Gulce Askin, MPH, were partially supported by the following grant: Clinical and Translational Science Center at Weill Cornell Medical College (1-UL1-TR002384-01).

\section{References}

1. Lortet-Tieulent J, Ferlay J, and Bray F, et al (2018) International Patterns and Trends in Endometrial Cancer Incidence, 1978-2013 JNCI J Natl Cancer Inst [Internet] 110(4) 354-361 [http://www.ncbi.nlm.nih.gov/pubmed/29045681] Date accessed: 26/09/16 https://doi. org/10.1093/jnci/djx214

2. Henley SJ, Miller JW, and Dowling NF, et al (2018) Uterine cancer incidence and mortality - United States, 1999-2016 MMWR Morb Mortal Wkly Rep [Internet] 67(48) 1333-1338 Date accessed: 14/12/18 https://doi.org/10.15585/mmwr.mm6748a1

3. Uterine Cancer-Cancer Stat Facts [Internet] https://seer.cancer.gov/statfacts/html/corp.html] Date accessed: 17/11/18

4. Bokhman JV (1983) Two pathogenetic types of endometrial carcinoma Gynecol Oncol [Internet] 15(1) 10-17 Date accessed: 26/09/19 https://doi.org/10.1016/0090-8258(83)90111-7

5. Getz G, Gabriel SB, and Cibulskis K, et al (2013) Integrated genomic characterization of endometrial carcinoma Nature [Internet] 497(7447) 67-73 Date accessed: 10/04/19 https://doi.org/10.1038/nature12113

6. Talhouk A, McConechy MK, and Leung S, et al (2017) Confirmation of ProMisE: a simple, genomics-based clinical classifier for endometrial cancer Cancer [Internet] 123(5) 802-813 Date accessed: 26/09/16 https://doi.org/10.1002/cncr.30496

7. Committee on Practice Bulletins-Gynecology, Society of Gynecologic Oncology (2014) ACOG Practice Bulletin No. 147: Lynch syndrome Obstet Gynecol [Internet] 124(5) 1042-1054 [http://content.wkhealth.com/linkback/openurl?sid=WKPTLP:landingpage \&an=00006250-201411000-00032] Date accessed: 17/11/18 https://doi.org/10.1097/01.A0G.0000456325.50739.72

8. Win AK, Jenkins MA, and Dowty JG, et al (2017) Prevalence and penetrance of major genes and polygenes for colorectal cancer Cancer Epidemiol Biomarkers Prev [Internet] 26(3) 404-412 [http://www.ncbi.nlm.nih.gov/pubmed/27799157] Date accessed: 7/09/19 https:// doi.org/10.1158/1055-9965.EPI-16-0693

9. Kahn RM, Gordhandas S, and Maddy BP, et al (2019) Universal endometrial cancer tumor typing: How much has immunohistochemistry, microsatellite instability, and MLH1 methylation improved the diagnosis of Lynch syndrome across the population? Cancer [Internet] [cited 2019 Sep 7] 125(18) 3172-3183 Date accessed:7/09/19 https://doi.org/10.1002/cncr.32203

10. Gupta S, Ahnen DJ, and Blanco AM, et al (2018) NCCN guidelines version 1.2018 genetic/familial high-risk assessment: colorectal NCCN guidelines panel disclosures continue [Internet] [https://www.nccn.org/professionals/physician_gls/pdf/genetics_colon.pdf] Date accessed: 30/12/18

11. Bruegl AS, Djordjevic B, and Urbauer DL, et al (2014) Utility of MLH1 methylation analysis in the clinical evaluation of Lynch Syndrome in women with endometrial cancer Curr Pharm Des [Internet] 20(11) 1655-1663 [http://www.ncbi.nlm.nih.gov/pubmed/23888949] Date accessed: 29/01/19 https://doi.org/10.2174/13816128113199990538

12. Cosgrove CM, Cohn DE, and Hampel H, et al (2017) Epigenetic silencing of MLH1 in endometrial cancers is associated with larger tumor volume, increased rate of lymph node positivity and reduced recurrence-free survival Gynecol Oncol 146(3) 588-595 Date accessed: 8/04/19 https://doi.org/10.1016/j.ygyno.2017.07.003

13. Lemery S, Keegan P, and Pazdur R (2018) First FDA approval agnostic of cancer site - when a biomarker defines the indication N Engl J Med [Internet] 377(15) 1409-1412 Date accessed: 27/12/18 https://doi.org/10.1056/NEJMp1709968 
14. Liberati A, Altman DG, and Tetzlaff J, et al (2009) The PRISMA statement for reporting systematic reviews and meta-analyses of studies that evaluate healthcare interventions: explanation and elaboration BMJ [Internet] [cited 2018 Nov 17] 339(jul21 1) b2700 Date accessed: 17/11/18 https://doi.org/10.1136/bmj.b2700

15. Anagnostopoulos A, McKay VH, and Cooper I, et al (2017) Identifying lynch syndrome in women presenting with endometrial carcinoma under the age of 50 years Int J Gynecol Cancer [Internet] [cited 2018 Nov 17] 27(5) 931-937 [http://insights.ovid.com/crossref ?an=00009577-201706000-00012] Date accessed: 17/11/18 https://doi.org/10.1097/IGC.0000000000000962

16. Berends MJW, Wu Y, and Sijmons RH, et al (2003) Toward new strategies to select young endometrial cancer patients for mismatch repair gene mutation analysis J Clin Oncol [Internet] [cited 2018 Nov 17] 21(23) 4364-4370 Date accessed: 17/11/18 https://doi. org/10.1200/JCO.2003.04.094

17. Lu KH, Schorge JO, and Rodabaugh KJ, et al (2007) Prospective determination of prevalence of lynch syndrome in young women with endometrial cancer J Clin Oncol [Internet] 25(33) 5158-5164 Date accessed: 16/11/18 https://doi.org/10.1200/JCO.2007.10.8597

18. Sutter C, Dallenbach-Hellweg G, and Schmidt D, et al (2004) Molecular analysis of endometrial hyperplasia in HNPCC-suspicious patients may predict progression to endometrial carcinoma Int J Gynecol Pathol [Internet] 23(1) 18-25 [https://insights.ovid.com/cross ref?an=00004347-200401000-00004] Date accessed: 16/11/18 https://doi.org/10.1097/01.pgp.0000101085.35393.4a

19. Dudley B, Brand RE, and Thull D, et al (2015) Germline MLH1 mutations are frequently identified in lynch syndrome patients with colorectal and endometrial carcinoma demonstrating isolated loss of pms2 immunohistochemical expression Am J Surg Pathol [Internet] 39(8) 1114-1120 [http://content.wkhealth.com/linkback/openurl?sid=WKPTLP:landingpage\&an=00000478-201508000-00012] Date accessed: 17/11/18 https://doi.org/10.1097/PAS.0000000000000425

20. Egoavil C, Alenda C, and Castillejo A, et al (2913) Prevalence of Lynch syndrome among patients with newly diagnosed endometrial cancers PLoS One [Internet] 8(11) e79737 Date accessed: 17/11/18 https://doi.org/10.1371/journal.pone.0079737

21. Ferguson SE, Aronson M, and Pollett A, et al (2014) Performance characteristics of screening strategies for Lynch syndrome in unselected women with newly diagnosed endometrial cancer who have undergone universal germline mutation testing Cancer [Internet] 120(24) 3932-3939 Date accessed: 16/11/18 https://doi.org/10.1002/cncr.28933

22. Goodfellow PJ, Billingsley CC, and Lankes HA, et al Combined Microsatellite instability, MLH1 methylation analysis, and immunohistochemistry for Lynch syndrome screening in endometrial cancers from GOG210: an NRG Oncology and Gynecologic Oncology Group Study J Clin Oncol [Internet] 33(36) 4301-4308 [http://ascopubs.org/doi/10.1200/JCO.2015.63.9518] Date accessed: 16/11/18

23. Goodfellow PJ, Buttin BM, and Herzog TJ, Rader JS, et al (2003) Prevalence of defective DNA mismatch repair and MSH6 mutation in an unselected series of endometrial cancers Proc Natl Acad Sci USA [Internet] [cited 2018 Nov 16] 100(10) 5908-5913 [http://www. ncbi.nlm.nih.gov/pubmed/12732731] Data accessed: 16/11/18 https://doi.org/10.1073/pnas.1030231100

24. Hampel H, Frankel W, and Panescu J, et al (2006) Screening for Lynch syndrome (hereditary nonpolyposis colorectal cancer) among endometrial cancer patients Cancer Res [Internet] [cited 2018 Nov 16] 66(15) 7810-7817 [http://www.ncbi.nlm.nih.gov/pubmed/16885385] https://doi.org/10.1158/0008-5472.CAN-06-1114

25. Leenen CHM, van Lier MGF, and van Doorn HC, et al (2012) Prospective evaluation of molecular screening for Lynch syndrome in patients with endometrial cancer $\leq 70$ years Gynecol Oncol [Internet] [cited 2018 Nov 16] 125(2) 414-420 [http://linkinghub.elsevier. com/retrieve/pii/S0090825812000820] https://doi.org/10.1016/j.ygyno.2012.01.049

26. Lin DI and Hecht JL (2016) Targeted screening with combined age- and morphology-based criteria enriches detection of Lynch syndrome in endometrial cancer Int J Surg Pathol [Internet] [cited 2018 Nov 16] 24(4) 297-305 https://doi.org/10.1177/1066896916629782

27. Mas-Moya J, Dudley B, and Brand RE, et al (2015) Clinicopathological comparison of colorectal and endometrial carcinomas in patients with Lynch-like syndrome versus patients with Lynch syndrome Hum Pathol [Internet] [cited 2018 Nov 16] 46(11) 1616-1625 [https:// linkinghub.elsevier.com/retrieve/pii/S0046817715002427] Date accessed: 16/11/18 https://doi.org/10.1016/j.humpath.2015.06.022 
28. Mills AM, Liou S, and Ford JM, et al (2014) Lynch syndrome screening should be considered for all patients with newly diagnosed endometrial cancer Am J Surg Pathol [Internet] 38(11) 1501-1509 [http://www.ncbi.nlm.nih.gov/pubmed/25229768] Date accessed: 16/11/18 https://doi.org/10.1097/PAS.0000000000000321

29. Mills AM, Sloan EA, and Thomas M, et al (2016) Clinicopathologic comparison of Lynch syndrome-associated and "Lynch-like" endometrial carcinomas identified on universal screening using mismatch repair protein immunohistochemistry Am J Surg Pathol [Internet] [cited 2018 Nov 16] 40(2) 1 [https://insights.ovid.com/crossref?an=00000478-900000000-98353] Date accessed: 16/11/18

30. Moline J, Mahdi H, and Yang B, et al (2013) Implementation of tumor testing for lynch syndrome in endometrial cancers at a large academic medical center Gynecol Oncol [Internet] [cited 2018 Nov 16] 130(1) 121-126 [https://linkinghub.elsevier.com/retrieve/pii/ S0090825813002424] Date accessed: 16/11/18 https://doi.org/10.1016/j.ygyno.2013.04.022

31. Najdawi F, Crook A, and Maidens J, et al (2017) Lessons learnt from implementation of a Lynch syndrome screening program for patients with gynaecological malignancy Pathology [Internet] [cited 2018 Nov 16] 49(5) 457-464 [https://linkinghub.elsevier.com/ retrieve/pii/S0031302517301708] Date accessed: 16/11/18 https://doi.org/10.1016/j.pathol.2017.05.004

32. Ollikainen M, Abdel-Rahman WM, and Moisio A-L, et al (2005) Molecular analysis of familial endometrial carcinoma: a manifestation of hereditary nonpolyposis colorectal cancer or a separate syndrome? J Clin Oncol [Internet] [cited 2018 Nov 16]; 23(21) 4609-4616 Date accessed: 16/11/18 https://doi.org/10.1200/JCO.2005.06.055

33. Rubio I, Ibáñez-Feijoo E, and Andrés L, et al (2016) Analysis of Lynch syndrome mismatch repair genes in women with endometrial cancer Oncology [Internet] 91(3) 171-176 [http://www.ncbi.nlm.nih.gov/pubmed/27398995] Date accessed: 16/11/18 https://doi. org/10.1159/000447972

34. Shin SH, Yu EJ, and Lee Y-K, et al (2015) Characteristics of hereditary nonpolyposis colorectal cancer patients with double primary cancers in endometrium and colorectum Obstet Gynecol Sci [Internet] 58(2) 112-116 [http://www.ncbi.nlm.nih.gov/pubmed/25798424] Date accessed: 16/11/18 https://doi.org/10.5468/ogs.2015.58.2.112

35. Watkins JC, Yang EJ, and Muto MG, et al (2017) Universal screening for mismatch-repair deficiency in endometrial cancers to identify patients with Lynch syndrome and Lynch-like syndrome Int J Gynecol Pathol [Internet] 36(2) 115-127 [https://insights.ovid.com/crossr ef?an=00004347-900000000-99374] Date accessed: 16/11/18 https://doi.org/10.1097/PGP.0000000000000312

36. Westin SN, Lacour RA, and Urbauer DL, et al (2008) Carcinoma of the lower uterine segment: a newly described association with Lynch syndrome J Clin Oncol [Internet] [cited 2018 Nov 16] 26(36) 5965-5971 [http://www.ncbi.nlm.nih.gov/pubmed/19001318] Date accessed: 16/11/18 https://doi.org/10.1200/JCO.2008.18.6296

37. Yoon SN, Ku J-L, and Shin Y-K, et al (2007) Hereditary nonpolyposis colorectal cancer in endometrial cancer patients Int J Cancer [Internet] 122(5) 1077-1081 Date accessed: 16/11/18 https://doi.org/10.1002/ijc.22986

38. Adar T, Rodgers LH, and Shannon KM, et al (2018) Universal screening of both endometrial and colon cancers increases the detection of Lynch syndrome Cancer [Internet] 124(15) 3145-3153 Date accessed: 16/11/18 https://doi.org/10.1002/cncr.31534

39. Backes FJ, Leon ME, and Ivanov I, et al (2009) Prospective evaluation of DNA mismatch repair protein expression in primary endometrial cancer Gynecol Oncol [Internet] 114(3) 486-490 [http://linkinghub.elsevier.com/retrieve/pii/S009082580900362X] Date accessed: 17/11/18 https://doi.org/10.1016/j.ygyno.2009.05.026

40. Banno K, Susumu N, and Hirao T, et al (2003) Identification of germline MSH2 gene mutations in endometrial cancer not fulfilling the new clinical criteria for hereditary nonpolyposis colorectal cancer Cancer Genet Cytogenet [Internet] 146(1) 58-65 [http://www.ncbi. nlm.nih.gov/pubmed/14499697] Date accessed: 17/11/18 https://doi.org/10.1016/S0165-4608(03)00157-2

41. Batte BAL, BruegI AS, and Daniels MS, et al (2014) Consequences of universal MSI/IHC in screening ENDOMETRIAL cancer patients for Lynch syndrome Gynecol Oncol [Internet] 134(2) 319-325 [http://www.ncbi.nlm.nih.gov/pubmed/24933100] Date accessed: 17/11/18 https://doi.org/10.1016/j.ygyno.2014.06.009 
42. Buchanan DD, Tan YY, and Walsh MD, et al (2014) Tumor mismatch repair immunohistochemistry and DNA MLH1 methylation testing of patients with endometrial cancer diagnosed at age younger than 60 years optimizes triage for population-level germline mismatch repair gene mutation testing J Clin Oncol [Internet] 32(2) 90-100 [http://www.ncbi.nlm.nih.gov/pubmed/24323032] Date accessed: 17/11/18 https://doi.org/10.1200/JCO.2013.51.2129

43. Dillon JL, Gonzalez JL, and Demars L, et al (2017) Universal screening for Lynch syndrome in endometrial cancers: frequency of germline mutations and identification of patients with Lynch-like syndrome Hum Pathol [Internet] [cited 2018 Nov 17] $70121-128$ [https://linkinghub.elsevier.com/retrieve/pii/S004681771730391X] Date accessed: 17/11/18 https://doi.org/10.1016/j.humpath.2017.10.022

44. Overbeek $\mathrm{LIH}$, Kets CM, and Hebeda KM, et al (2007) Patients with an unexplained microsatellite instable tumour have a low risk of familial cancer Br J Cancer [Internet] 96(10) 1605-1612 Date accessed: 30/12/18 https://doi.org/10.1038/sj.bjc.6603754

45. Meyer LA, Broaddus RR, and Lu KH (2009) Endometrial cancer and Lynch syndrome: clinical and pathologic considerations Cancer Control [Internet] 16(1) 14-22 [http://www.ncbi.nlm.nih.gov/pubmed/19078925] Date accessed: 31/08/19 https://doi. org/10.1177/107327480901600103

46. Cohn DE, Pavelka JC, and Frankel WL, et al (2008) Correlation between patient weight and defects in DNA mismatch repair: is this the link between an increased risk of previous cancer in thinner women with endometrial cancer? Int J Gynecol Cancer [Internet] 18(1) 136140 [http://www.ncbi.nlm.nih.gov/pubmed/17466051] Date accessed: 14/01/19 https://doi.org/10.1111/j.1525-1438.2007.00964.x

47. Rodríguez-Soler M, Pérez-Carbonell L, and Guarinos C, et al (2013) Risk of cancer in cases of suspected Lynch syndrome without germline mutation Gastroenterology [Internet] 144(5) 926-932.e1 [http://www.ncbi.nlm.nih.gov/pubmed/23354017] Date accessed: 14/01/19 https://doi.org/10.1053/j.gastro.2013.01.044

48. Watson P, Lin KM, and Rodriguez-Bigas MA, et al (1998) Colorectal carcinoma survival among hereditary nonpolyposis colorectal carcinoma family members Cancer [Internet] 83(2) 259-266 Date accessed: 6/12/18 https://doi.org/10.1002/(SICI)10970142(19980715)83:2<259::AID-CNCR9>3.0.CO;2-L

49. Gryfe R, Kim H, and Hsieh ETK, et al (2000) Tumor microsatellite instability and clinical outcome in young patients with colorectal cancer N Engl J Med [Internet] 342(2) 69-77 Date accessed: 14/01/19 https://doi.org/10.1056/NEJM200001133420201

50. MacDonald ND, Salvesen HB, and Ryan A, et al (2000) Frequency and prognostic impact of microsatellite instability in a large population-based study of endometrial carcinomas Cancer Res [Internet] 60(6) 1750-1752 [http://www.ncbi.nlm.nih.gov/pubmed/10749149] Date accessed: 19/11/18

51. Zighelboim I, Goodfellow PJ, and Gao F, et al (2007) Microsatellite instability and epigenetic inactivation of MLH1 and outcome of patients with endometrial carcinomas of the endometrioid type J Clin Oncol 25(15) 2042-2048 https://doi.org/10.1200/JCO.2006.08.2107 PMID: 17513808

52. Caduff RF, Johnston CM, and Svoboda-Newman SM, et al (1996) Clinical and pathological significance of microsatellite instability in sporadic endometrial carcinoma Am J Pathol 148(5) 1671-1678 PMID: 8623934 PMCID: 1861548

53. Basil JB, Goodfellow PJ, and Rader JS (2000) Clinical significance of microsatellite instability in endometrial carcinoma Cancer 89(8) 1758-1764 https://doi.org/10.1002/1097-0142(20001015)89:8<1758::AID-CNCR16>3.0.CO;2-A PMID: 11042571

54. Fiumicino S, Ercoli A, and Ferrandina G, et al Microsatellite instability is an independent indicator of recurrence in sporadic stage I-II endometrial adenocarcinoma J Clin Oncol 19(4) 1008-1014 PMID: 11181663

55. Black D, Soslow RA, and Levine DA, et al (2006) Clinicopathologic significance of defective DNA mismatch repair in endometrial carcinoma J Clin Oncol 24(11) 1745-1753 https://doi.org/10.1200/JCO.2005.04.1574 PMID: 16549821

56. Cohn DE, Frankel WL, and Resnick KE, et al (2006) Improved survival with an intact DNA mismatch repair system in endometrial cancer Obstet Gynecol 108(5) 1208-1215 https://doi.org/10.1097/01.AOG.0000239097.42987.0c PMID: 17077244 
57. Shikama A, Minaguchi T, and Matsumoto K, et al (2016) Clinicopathologic implications of DNA mismatch repair status in endometrial carcinomas Gynecol Oncol [Internet] 140(2) 226-233 [https://linkinghub.elsevier.com/retrieve/pii/S0090825815302043] Date accessed: 19/11/18 https://doi.org/10.1016/j.ygyno.2015.11.032

58. Diaz-Padilla I, Romero N, and Amir E, et al (2013) Mismatch repair status and clinical outcome in endometrial cancer: a systematic review and meta-analysis Crit Rev Oncol Hematol 88(1) 154-167 https://doi.org/10.1016/j.critrevonc.2013.03.002 PMID: 23562498

59. Stelloo E, Nout RA, and Osse EM, et al (2016) Improved risk assessment by integrating molecular and clinicopathological factors in early-stage endometrial cancer - combined analysis of PORTEC cohorts Clin Cancer Res [Internet] 22(16) 4215-4224 Date accessed: 29/05/20 https://doi.org/10.1158/1078-0432.CCR-15-2878

60. Backes FJ, Haag J, and Cosgrove CM, et al (2019) Mismatch repair deficiency identifies patients with high-intermediate-risk (HIR) endometrioid endometrial cancer at the highest risk of recurrence: a prognostic biomarker Cancer [Internet] 125(3) 398-405 Date accessed: 28/04/19 https://doi.org/10.1002/cncr.31901 


\section{Supplementary tables}

Supplementary Table 1. Full Ovid MEDLINE systematic review search strategy.

\begin{tabular}{|c|c|}
\hline 1. Lynch Syndrome II/ & 42. immunoenzymology.tw. \\
\hline 2. hereditary nonpolyposis colon cancer.tw. & 43. antigen purification.tw. \\
\hline 3. hereditary non polyposis colon cancer.tw. & 44. antigen isolation.tw. \\
\hline 4. hereditary nonpolyposis colorectal cancer.tw. & 45. fluorescent antiglobulin*.tw. \\
\hline 5. hereditary non polyposis colorectal cancer.tw. & 46. fluorescent inhibition.tw. \\
\hline 6. HNPCC.tw. & 47. immunoassay/ \\
\hline 7. (lynch adj3 syndome*).tw & 48. immunoassay*.tw. \\
\hline 8. or/1-7 & 49. antibody assay*.tw. \\
\hline 9. DNA Methylation/ & 50. antibody test*.tw. \\
\hline 10. DNA Methylation*.tw. & 51. antigen assay*.tw. \\
\hline 11. deoxyribonucleic acid methylation.tw. & 52. immune assay*.tw. \\
\hline 12. DNA hypermethylation.tw. & 53. immuno assay*.tw. \\
\hline 13. DNA hypomethylation.tw. & 54. immunoanalysis.tw. \\
\hline 14. methylated deoxyribonucleic acid.tw. & 55. enzyme linked immunosorbent assay*.tw. \\
\hline 15. methylated DNA.tw. & 56. electroimmunoassay*.tw. \\
\hline 16. Methylation Analysis.tw. & 57. immunospot assay*.tw. \\
\hline 17. exp Immunochemistry/ & 58. immunospot assay*.tw. \\
\hline 18. immunochemistry.tw. & 59. immunoelectrophoresis.tw. \\
\hline 19. immunohistochemistry.tw. & 60. immunoradiometric assay*.tw. \\
\hline 20. immunolabeling.tw. & 61. interferon gamma release assay*.tw. \\
\hline 21. immunogold.tw. & 62. radioimmunoassay*.tw \\
\hline 22. immunocytochemistry.tw. & 63. immunoblotting/ \\
\hline 23. fluorescent antibody technique/ & 64. immunoblot*.tw. \\
\hline 24. fluorescent antibod*.tw & 65. immunocytochemistry.tw. \\
\hline 25. Immunofluorescence.tw. & 66. cytoimmunochemistry.tw. \\
\hline 26. fluorescent protein tracing*.tw & 67. immunocytochemical staining*.tw. \\
\hline 27. coon* techni*.tw & 68. immunodiffusion/ \\
\hline 28. fluorescent antinuclear antibody test*.tw & 69. immunodiffusion.tw. \\
\hline 29. fluoroimmunoassay*.tw & 70. antibody agar plate method*.tw. \\
\hline 30. immunofluorometric assay*.tw & 71. immune diffusion.tw. \\
\hline 31. flourescence polarization immunoassay*.tw & 72. immunoelectrodiffusion.tw. \\
\hline 32. antigen staining.tw. & 73. ouchterlony*.tw. \\
\hline 33. immunostaining.tw. & 74. immunoprecipitation/ \\
\hline 34. antigen retrieval.tw. & 75. immunoprecipitat*.tw. \\
\hline 35. immunoperoxidase staining.tw. & 76. radionimmunoprecipitation.tw. \\
\hline 36. goodpasture staining*.tw & 77. Microsatellite Instability/ \\
\hline 37. peroxidase stain*.tw. & 78. microsatellite Instability.tw. \\
\hline 38. immunoperoxidase technique*.tw. & 79. (replication adj3 phenotype).tw. \\
\hline 39. immunophosphatase technique*.tw. & 80. tumour typ*.tw. \\
\hline 40. immunochemical method*.tw. & 81. or/9-80 \\
\hline 41. immunochemical stud*.tw. & 82. 8 and 81 \\
\hline
\end{tabular}


Supplementary Table 2. Tumour testing performed, and studies including clinicopathologic data.

\begin{tabular}{|c|c|c|c|c|c|c|c|c|c|c|}
\hline \multirow[b]{2}{*}{ Study } & \multicolumn{4}{|c|}{ Tumour testing } & \multicolumn{3}{|c|}{ Age } & \multicolumn{3}{|c|}{ BMI } \\
\hline & $\mathrm{IHC}$ & MSI & $\begin{array}{c}\text { MLH1 } \\
\text { Methylation }\end{array}$ & $\begin{array}{c}\text { Tumour } \\
\text { Sequencing }\end{array}$ & Intact & $\begin{array}{c}\text { MMR- } \\
\text { deficient }\end{array}$ & $\begin{array}{c}\text { Lynch } \\
\text { syndrome }\end{array}$ & Intact & $\begin{array}{l}\text { MMR- } \\
\text { deficient }\end{array}$ & $\begin{array}{c}\text { Lynch } \\
\text { syndrome }\end{array}$ \\
\hline Adar Tomer 2018 [38] & $x$ & & $x$ & & & & $x$ & & & \\
\hline Anagnostopoulos 2017 [15] & $X$ & $\mathrm{X}$ & $X$ & & & & & & $\mathrm{x}$ & $\mathrm{x}$ \\
\hline Backes 2009 [39] & $x$ & & & & $x$ & & & & & \\
\hline Banno 2003 [40] & & $x$ & & & $x$ & & & & & \\
\hline Batte 2014 [41] & $x$ & & $x$ & & & & $x$ & & & \\
\hline Berends 2003 [16] & $x$ & $\mathrm{X}$ & & & & & & & & \\
\hline Buchanan 2014 [42] & $x$ & & $x$ & & & & $x$ & & & $x$ \\
\hline Dillon 2017 [43] & $x$ & & $x$ & & $x$ & $\mathrm{x}$ & $x$ & $x$ & $x$ & $x$ \\
\hline Dudley 2015 [19] & $x$ & & & & & & & & & \\
\hline Egoavil 2013 [20] & $x$ & $\mathrm{x}$ & $x$ & & $x$ & & $x$ & & & \\
\hline Ferguson 2014 [21] & $x$ & $x$ & & & & $x$ & $x$ & & $x$ & $x$ \\
\hline Goodfellow 2015 [22] & $x$ & $\mathrm{x}$ & $x$ & & & $x$ & $x$ & & & \\
\hline Goodfellow 2003 [23] & & $x$ & $x$ & $x$ & $x$ & & $x$ & & & \\
\hline Hampel 2006 [24] & $x$ & $x$ & $x$ & $x$ & & & $x$ & & & \\
\hline Leenen 2012 [25] & $x$ & $x$ & $x$ & & $x$ & $x$ & $x$ & & & \\
\hline Lin 2015 [26] & $x$ & & $x$ & & & $x$ & $x$ & & & \\
\hline Lu 2007 [17] & $x$ & $\mathrm{X}$ & $x$ & & & $x$ & $x$ & & $x$ & $x$ \\
\hline Mas-Moya 2015 [27] & $x$ & & $x$ & & & $\mathrm{x}$ & $x$ & & & \\
\hline Mills 2014 [28] & $x$ & & $x$ & & & & & & & \\
\hline Mills 2016 [29] & $x$ & & $x$ & & & $x$ & $x$ & & & \\
\hline Moline 2013 [30] & $x$ & $\mathrm{X}$ & $x$ & & $x$ & $x$ & $x$ & $x$ & & \\
\hline Najdawi 2017 [31] & $x$ & & $x$ & $x$ & $x$ & $x$ & $\mathrm{x}$ & & & \\
\hline Ollikainen 2005 [32] & $x$ & $x$ & $x$ & & & & & & & \\
\hline Rubio 2016 [33] & $x$ & $x$ & & & & $x$ & $x$ & & & \\
\hline Shin 2015 [34] & $x$ & $x$ & & & $x$ & & $x$ & & & \\
\hline Sutter 2004 [18] & $x$ & $x$ & & $x$ & $x$ & & & & & \\
\hline Watkins 2017 [35] & $x$ & & $x$ & & & & & & & \\
\hline Westin 2008 [36] & $x$ & $x$ & $x$ & & & $x$ & $x$ & & $x$ & $x$ \\
\hline Yoon 2008 [37] & $x$ & $x$ & $x$ & & & & & & & \\
\hline
\end{tabular}

$X$, study includes data in the specified population. 
Supplementary Table 2. Continued

\begin{tabular}{|c|c|c|c|c|c|c|c|c|c|}
\hline \multirow[b]{2}{*}{ Study } & \multicolumn{3}{|c|}{ Stage } & \multicolumn{3}{|c|}{ Grade } & \multicolumn{3}{|c|}{ Histology } \\
\hline & Intact & $\begin{array}{l}\text { MMR- } \\
\text { deficient }\end{array}$ & $\begin{array}{l}\text { Lynch syn- } \\
\text { drome }\end{array}$ & Intact & $\begin{array}{c}\text { MMR- } \\
\text { deficient }\end{array}$ & $\begin{array}{l}\text { Lynch syn- } \\
\text { drome }\end{array}$ & Intact & $\begin{array}{l}\text { MMR- } \\
\text { deficient }\end{array}$ & $\begin{array}{c}\text { Lynch } \\
\text { syndrome }\end{array}$ \\
\hline \multicolumn{10}{|l|}{ Adar Tomer 2018 [38] } \\
\hline Anagnostopoulos 2017 [15] & & $x$ & $x$ & & $x$ & $x$ & & & \\
\hline Backes 2009 [39] & $x$ & $x$ & & $x$ & $x$ & & $x$ & $x$ & \\
\hline Banno 2003 [40] & $x$ & & & $x$ & & $x$ & $x$ & & \\
\hline Batte 2014 [41] & & & $x$ & & & $x$ & & & $x$ \\
\hline \multicolumn{10}{|l|}{ Berends 2003 [16] } \\
\hline Buchanan 2014 [42] & & & $x$ & & & $x$ & & & $x$ \\
\hline Dillon 2017 [43] & $x$ & $x$ & $x$ & $x$ & $x$ & $x$ & $x$ & $x$ & $x$ \\
\hline \multicolumn{10}{|l|}{ Dudley 2015 [19] } \\
\hline Egoavil 2013 [20] & & & & $x$ & & & $x$ & & $x$ \\
\hline Ferguson 2014 [21] & & & $x$ & & & $x$ & & & $x$ \\
\hline \multicolumn{10}{|l|}{ Goodfellow 2015 [22] } \\
\hline Goodfellow 2003 [23] & & & & & & & $x$ & & $x$ \\
\hline Hampel 2006 [24] & & & & & & & & & $x$ \\
\hline Leenen 2012 [25] & $x$ & & & $x$ & $x$ & $x$ & $x$ & $x$ & $x$ \\
\hline \multicolumn{10}{|l|}{ Lin 2015 [26] } \\
\hline Lu 2007 [17] & & $x$ & $x$ & & & & & $x$ & $x$ \\
\hline Mas-Moya 2015 [27] & & & & & $x$ & $x$ & & $x$ & $x$ \\
\hline \multicolumn{10}{|l|}{ Mills 2014 [28] } \\
\hline Mills 2016 [29] & & $x$ & $x$ & & $x$ & $x$ & & $x$ & $x$ \\
\hline Moline 2013 [30] & $x$ & & & $x$ & $x$ & $x$ & $x$ & $x$ & $x$ \\
\hline Najdawi 2017 [31] & $x$ & $x$ & $x$ & $x$ & $x$ & $x$ & $x$ & $x$ & $x$ \\
\hline \multicolumn{10}{|l|}{ Ollikainen 2005 [32] } \\
\hline Rubio 2016 [33] & $x$ & $x$ & $x$ & & & & & & \\
\hline Shin 2015 [34] & & & & & & & $x$ & & $x$ \\
\hline Sutter 2004 [18] & $x$ & & & $x$ & & & $x$ & & \\
\hline \multicolumn{10}{|l|}{ Watkins 2017 [35] } \\
\hline Westin 2008 [36] & & & & & $x$ & $x$ & & $x$ & $x$ \\
\hline Yoon 2008 [37] & & & & & & & & & \\
\hline
\end{tabular}

$X$, study includes data in the specified population. 